\title{
A dimensão técnico-operativa no trabalho do(a) assistente social no contexto do internamento de um centro hospitalar de reabilitação
}

\section{The technical-operative dimension in the work of the social assistant in the context of the internation of a hospital rehabilitation center}

DOI: $10.46919 / \operatorname{archv} 1 n 2-003$

Recebimento dos originais: 10/01/2020

Aceitação para publicação: 10/02/2020

\author{
Gabriela Rodrigues Mattos \\ Discente do curso de serviço social \\ Pontifícia Universidade Católica do Paraná \\ R. Imac. Conceição, 1155 - Prado Velho, Curitiba - PR \\ E-mail: mattos.gabriela@outlook.com \\ Vanilza Santos Cunha \\ Docente e assistente social \\ Ministério da Saúde \\ Rua Francisco Rocha 1750 apto 703, Curitiba - PR \\ E-mail: vanilza.cunha@ufpr.br
}

\begin{abstract}
RESUMO
O presente artigo versa sobre o papel da dimensão técnico-operativa na prática profissional do(a) assistente social e suas contribuições no contexto do internamento de um Centro Hospitalar de Reabilitação. A metodologia utilizada consistiu na realização de pesquisa bibliográfica em artigos científicos, livros e demais produções teóricas e materiais disponíveis que pudessem contribuir com a análise pretendida. Partiu-se da explanação do que consiste a categoria instrumentalidade, perpassando as dimensões profissionais a fim de se chegar aos instrumentos de trabalho indiretos, presentes na dimensão técnico-operativa. Tomou-se como exemplo para a pesquisa o internamento do Centro Hospitalar de Reabilitação Ana Carolina Moura Xavier- CHR, situado na cidade de Curitiba, no bairro Cabral. Assim, traçou-se a relação dos instrumentos de trabalho indiretos na prática do(a) assistente social no contexto do espaço socioocupacional mencionado. À partir da realização desta pesquisa foi possível constatar a importância destes instrumentos enquanto meios de registro e documentação, viabilizando a sistematização do exercício profissional, o que gera contribuições significativas para a prática profissional, pois proporciona o diálogo entre os(as) profissionais, o aprimoramento da prática e incide favoravelmente no que se refere à identidade profissional neste local; e para o espaço socioocupacional, pois permite o compartilhamento e troca de informações com a equipe multiprofissional e o processo de construção da identidade do próprio espaço.
\end{abstract}

Palavras-chave: Dimensão técnico-operativa, Instrumentos indiretos, Registro e documentação, Internamento, Centro Hospitalar de Reabilitação. 


\section{ABSTRACT}

This article deals with the role of the technical-operative dimension in the professional practice of the social worker and their contributions in the context of the internment of a Hospital Rehabilitation Center. The methodology used consisted of conducting bibliographic research on scientific articles, books and other theoretical productions and available materials that could contribute to the intended analysis. It started with the explanation of what constitutes the instrumentality category, going through the professional dimensions in order to arrive at the indirect work instruments, present in the technicaloperative dimension. As an example for the research, the internment of the Ana Carolina Moura XavierCHR Hospital Rehabilitation Center, located in the city of Curitiba, in the Cabral neighborhood, was taken as an example. Thus, the list of indirect work instruments in the practice of the social worker was traced in the context of the mentioned socio-occupational space. From the realization of this research it was possible to verify the importance of these instruments as means of recording and documentation, enabling the systematization of the exercise professional, which generates significant contributions to professional practice, as it provides the dialogue between professionals, the improvement of practice and has a favorable impact on professional identity in this place; and for the socio-occupational space, as it allows the sharing and exchange of information with the multiprofessional team and the process of building the identity of the space itself.

Keywords: Technical-operative dimension, Indirect instruments, Registration and documentation, Internment, Hospital Rehabilitation Center.

\section{INTRODUÇÃO}

Este artigo se propõe a verificar quais as contribuições trazidas a partir da utilização dos instrumentos de trabalho indiretos, ou por escrito, na prática do(a) assistente social no contexto do internamento de um Centro Hospitalar de Reabilitação, uma vez que, segundo Sousa (2008, p. 129), “[...] a utilização dos instrumentos de trabalho por escrito também possui uma fundamental importância: é aqui que se torna possível ao Assistente Social sistematizar a prática”.

Assim sendo, por meio de pesquisa bibliográfica em livros, artigos científicos e demais materiais teóricos disponíveis, construir-se-á uma análise textual que abordará, num primeiro momento, a categoria da instrumentalidade no âmbito do Serviço Social e as três dimensões do exercício profissional, aprofundando-se na dimensão técnico-operativa e perpassando a temática dos instrumentais técnicooperativos a fim de alcançar uma explanação acerca dos instrumentos de trabalho indiretos, que visará demonstrar seu papel frente ao registro e documentação do exercício profissional.

Num segundo momento, será feita uma construção buscando explicitar o funcionamento da instituição elencada para a análise, tomando como exemplo o internamento do Centro Hospitalar de Reabilitação Ana Carolina Moura Xavier- CHR, localizado na cidade de Curitiba, no bairro Cabral, e a inserção do Serviço Social nele, até que se possa finalmente traçar a relação que há entre os instrumentos de trabalho indiretos e a prática do(a) assistente social no referido espaço, visando verificar, portanto, 
quais contribuições sua utilização e valorização podem trazer para a prática profíssional e para a instituição.

\section{UMA BREVE ANÁLISE A RESPEITO DA INSTRUMENTALIDADE EDAS TRÊS DIMENSÕES DO EXERCÍCIO PROFISSIONAL COM ENFOQUE NA DIMENSÃO TÉCNICO- OPERATIVA E NOS INSTRUMENTOS DE TRABALHO INDIRETOS}

A instrumentalidade, no âmbito do Serviço Social, segundo Guerra (2000), refere-se a uma capacidade profissional adquirida com o próprio fazer profissional, à medida que se concretiza e alcança objetivos e finalidades, sendo construída e reconstruída no processo sócio-histórico.

Isso sugere pensar a instrumentalidade para além de um conjunto de instrumentos e técnicas necessários à prática profissional, uma vez que ela se constitui como instrumento de mediação, sendo capaz de transformar o contexto de ações puramente instrumentais em uma ação profissional competente e crítica, a partir de uma articulação teleológica. A instrumentalidade constitui-se, portanto, em meio de reconhecimento social da profissão, pois permite, devido ao fato de ser uma propriedade sócio-histórica, que as demandas que se apresentam possam ser atendidas e que os objetivos sociais e profissionais possam ser conquistados (GUERRA, 2000).

É nesse sentido que reconhecer a instrumentalidade como mediação exige articular três dimensões imprescindíveis para o fazer profissional: a dimensão teórico-metodológica, ético-política e técnicooperativa, sendo estas consideradas

[...] requisitos fundamentais que permite ao profissional colocar-se diante das situações com as quais se defronta, vislumbrando com clareza os projetos societários, seus vínculos de classe, e seu próprio processo de trabalho (ABEPSS,1996, p.13).

É importante pontuar, segundo Guerra (2012), que não se pode negar a unidade existente entre as três dimensões, devendo estas estarem sempre articuladas no trabalho do(a) assistente social, a fim de que não se sustente discursos como os de que há um descolamento entre teoria e prática, uma vez que a apreensão particularizada de cada dimensão pode implicar, por exemplo, em compreensões equivocadas da teoria e da falsa constatação de que a prática se resume ao uso de instrumentos e técnicas.

Assim sendo, em suma, a dimensão teórico-metodológica é aquela que se refere à capacidade de compreensão e apreensão das teorias e métodos e no que esses se relacionam com a prática, sendo entendida por Santos (2006) como meio de apreensão da realidade por parte do(a) assistente social, bem como das expressões da questão social que a permeiam, sendo possível, a partir disso, enxergar contradições e direções. É válido lembrar que esta não se configura como ciência, mas se utiliza das 
ciências sociais e humanas para o exercício profissional e, como não há neutralidade, a profíssão optou pela perspectiva da Teoria Social Crítica Marxista para análise da realidade social.

Já a dimensão ético-política compreende, de acordo com Iamamoto (2001), uma prática social que se direciona à criação de novos valores, significados e vivências, sendo a dimensão que manifesta o compromisso da profissão frente ao enfrentamento das expressões da questão social, e que se expressa no processo de trabalho por meio de ações conscientes e críticas ligadas ao posicionamento de defesa dos direitos dos(as) usuários(as). Essa dimensão possui relação direta com a defesa do atual Projeto ÉticoPolítico da profissão, tendo, portanto, como base central o Código de Ética do(a) Assistente Social e seus 11 princípios, que defendem a liberdade como valor ético central. Esta dimensão refuta o tradicionalismo e a neutralidade.

Quanto à dimensão técnico-operativa, conforme Mioto e Lima (2009, p. 36), esta é "entendida como o espaço de trânsito entre o projeto profissional e a formulação de respostas inovadoras às demandas que se impõem no cotidiano dos assistentes sociais [...]”, sendo esta a dimensão que dá visibilidade à profissão e que permite dar concretude aos objetivos profissionais. Ela não se trata apenas dos instrumentos, mas de definição de objetivos, finalidades, conhecimento, linguagem, articulação das condições objetivas e subjetivas, enfim, uma série de procedimentos e de ações que o(a) profissional pode adotar visando uma determinada finalidade.

\subsection{A DIMENSÃO TÉCNICO-OPERATIVAE OS INSTRUMENTAIS TÉCNICO-OPERATIVOS}

Uma vez que se pretende chegar à análise dos instrumentos de trabalho indiretos, ou seja, dos instrumentos de registro profissional, no contexto do internamento de um Centro Hospitalar de Reabilitação, faz-se necessário um breve aprofundamento a respeito da dimensão técnico-operativa e dos instrumentais técnico-operativos.

Conforme já colocado, a dimensão técnico-operativa abrange os instrumentos, técnicas e procedimentos utilizados pelo(a) assistente social em sua intervenção profissional, sendo que, para desenvolver os procedimentos, que são as avaliações, o planejamento, os encaminhamentos, etc., responsáveis por expressar o fazer profissional, o(a) profissional se utiliza das ferramentas, ou instrumentos e técnicas, podendo ser citados como exemplo as entrevistas, as reuniões, as visitas domiciliares, etc. (SANTOS et al., 2012).

É nesse sentido que se pode dar destaque à essa dimensão

enquanto dimensão que em sua especificidade é a mais aproximada da prática profissional, e, que por ser assim, propriamente dita, necessariamente, expressa e contém as demais dimensões. Ou seja, as ações expressam as concepções teórico-metodológica e ético-política do profissional 
mesmo que ele não tenha clareza de suas concepções e de seus valores. Nesta direção, a dimensão técnico-operativa envolve um conjunto de estratégias, táticas e técnicas instrumentalizadoras da ação, que efetivam o trabalho profissional, e que expressam uma determinada teoria, um método, uma posição política e ética (SANTOS, 2013, p. 2).

Diante disso, cabe o reforço de que não se pode, portanto, considerá-la em detrimento das dimensões teórico-metodológica e ético-política, uma vez que é a interlocução permanente entre as três que fornece os elementos necessários para concretizar o alcance e direcionamento da intervenção profissional.

Quanto aos instrumentais técnico-operativos, estes se constituem enquanto parte intrínseca e fundamental da dimensão técnico-operativa, e são um conjunto de instrumentos e técnicas de trabalho que estão dialeticamente articulados, e, conforme se constituem como produtos da ação humana, são elementos que mediam e potencializam a ação e o trabalho profissional.

Referente aos instrumentos de trabalho há uma classificação utilizada por Sousa (2008) que faz uma distinção entre eles em diretos e indiretos, e que será empregada aqui para fins de melhor contribuir com o objetivo dessa pesquisa, que é o enfoque nos ditos indiretos.

O autor perpassa pela análise da linguagem no âmbito da prática profissional do(a) assistente social, apontando-a como instrumento número um de todos(as) os(as) profissionais, uma vez que ela possibilita o processo da comunicação. É colocado por ele que "é a partir das formas de comunicação que se estabelecem no espaço das instituições onde trabalha o Assistente Social que este profissional poderá construir e utilizar instrumentos e técnicas de intervenção social” (SOUSA, 2008, p. 125).

É a partir de então que, de acordo com o autor, pode-se elencar duas categorias de linguagem no âmbito do Serviço Social, sendo elas a linguagem a oral, ou direta, e a linguagem escrita, ou indireta, cabendo, dentro de cada uma, a referida distinção entre os instrumentos de trabalho diretos e indiretos.

Os instrumentos diretos, em suma, são aqueles que proporcionam uma interação direta, ou seja, são considerados instrumentos face a face, que contam com a utilização do diálogo e/ou contato entre aqueles(as) que interagem. Entre eles podem ser citadas as visitas domiciliares e institucionais, os atendimentos e reuniões, também podendo ser grupais ou individuais, as dinâmicas e trabalhos em grupo, as entrevistas, entre outros.

Já os instrumentos indiretos consistem no registro da interação que se realiza a partir da utilização dos instrumentos face a face, ou seja, dos instrumentos diretos, independente da metodologia utilizada. Entre os instrumentos indiretos podem ser citados os relatórios sociais, atas de reuniões, laudos, perícias e pareceres sociais, o livro de registro ou de plantão social, diário de campo, entre outros. 


\subsubsection{Os instrumentos de trabalho indiretos: características e relevância}

Conforme já colocado, os instrumentos de trabalho indiretos se referem àqueles utilizados no registro da interação realizada por meio da utilização primeira dos instrumentos diretos. Nesse sentido, a utilização dos instrumentos indiretos vem sempre após a utilização dos diretos, de modo que se compreende seu papel frente ao registro das atividades práticas que foram desenvolvidas pelo(a) profissional.

Segundo Ihara e Liberato (2010), o uso dos instrumentos de registro no âmbito do Serviço Social reflete na documentação, sendo essa um elemento de grande importância para a prática profissional.

Conforme pontuam as autoras,

A documentação é a parte concreta da metodologia do Serviço Social, que permite não somente registrar as observações e atividades, mas também analisar os processos, avaliar as condições, os problemas encontrados, os resultados, enfim sistematizar as ações (IHARA; LIBERATO, 2010, p. $15)$.

Nesse sentido, o registro enquanto componente da documentação no campo do Serviço Social se torna imprescindível ao desempenho profissional, não podendo ser um processo negligenciado, uma vez que contribui para a sistematização da prática, conforme salienta Sousa (2008), possibilitando que haja um processo de ação-reflexão, bem como a apreensão de elementos que contribuam com a análise, intervenção, com a postura crítica e investigativa e com o próprio aprimoramento da prática.

\section{A PRÁtica PROFISSIONAL DO(A) ASSISTENTE SOCIAL NO CONTEXTO DO INTERNAMENTO DE UM CENTRO HOSPITALAR DE REABILITAÇÃO E SUA RELAÇÃO COM OS INSTRUMENTOSDE TRABALHO INDIRETOS}

\subsection{SOBRE O FUNCIONAMENTO DE UM INTERNAMENTO EM UM CHR}

Para dar segmento à análise da relação do uso dos instrumentos de trabalho indiretos na prática do(a) assistente social no contexto do internamento de um Centro Hospitalar de Reabilitação é preciso compreender, antes de mais nada, a forma pela qual se dá a organização e o fluxo, ou seja, o funcionamento deste espaço, considerando os(as) profissionais que perpassam as etapas deste trabalho bem como onde se encaixa o Serviço Social e quais vem a ser as atividades exercidas pelo(a) assistente social.

Tomar-se-á aqui, como exemplo, o internamento do Centro Hospitalar de Reabilitação Ana Carolina Moura Xavier - CHR. 
O internamento nessa instituição se pauta na intenção de intensificar as terapias do processo de tratamento de reabilitação, permitindo ao paciente uma reabilitação mais direcionada e que, portanto, possibilita lidar com os traumas sofridos de modo que sequelas e deformidades não se tornem definitivas nem tampouco estruturadas, além de viabilizar maior independência ao paciente, que, posteriormente, pode dar continuidade em seu tratamento no Ambulatório do CHR ou em seu município de origem.

O desenvolvimento do trabalho do internamento no CHR inicia-se a partir do Núcleo Interno de Regulação (NIR), em que fazem parte a Medicina e o Serviço Social. Cabe ao NIR o primeiro diálogo com o hospital de origem do(a) paciente. Uma vez que ocorre o encaminhamento, via e-mail, por parte de outra instituição, o NIR é o responsável pelo recebimento do formulário e do resumo clínico do(a) paciente, sendo posteriormente realizada a análise dos dados com a finalidade de verificar se há indicação para avaliação de internamento para fins de reabilitação na instituição.

Em seguida, o próximo procedimento é a avaliação do(a) paciente, realizado por uma equipe multiprofissional composta pela Medicina, Enfermagem, Nutrição, Fonoaudiologia e Serviço Social, e se necessário os(as) profissionais de Fisioterapia e Terapia Ocupacional. É nesse processo que se avalia mais detalhadamente as condições em que o(a) paciente se encontra a fim de constatar se este(a) se encontra elegível para o internamento, havendo, desde já, uma aproximação e articulação dos(as) profissionais que, posteriormente, serão aqueles(as) que realizarão o processo de reabilitação do(a) paciente no caso de admissão.

Feita a admissão do(a) paciente, dá-se início ao seu processo de tratamento de reabilitação, momento em que, novamente, deve ocorrer uma articulação da equipe técnica para que sejam adotadas as melhores medidas, procedimentos e encaminhamentos de acordo com o diagnóstico, necessidades e limitações de cada paciente, até o momento de sua alta hospitalar. Ainda dentro do processo de reabilitação, é verificada pela equipe a necessidade de reabilitação posterior à alta hospitalar em regime ambulatorial na instituição, sendo que, caso o(a) paciente necessite, é organizado um plano terapêutico e um cronograma que atenda a essa demanda. $\mathrm{Na}$ ocasião de o(a) paciente não estar elegível para o tratamento ambulatorial, o internamento oferta um programa de orientação para os cuidadores(as) que visa capacitá-los(as) em diversos aspectos para a provisão adequada de cuidados.

\subsection{A INSERÇAO DO SERVIÇO SOCIAL NO INTERNAMENTO DE UM CHR}

Conforme já colocado, e tomando ainda como o exemplo o internamento do Centro Hospitalar de Reabilitação Ana Carolina Moura Xavier - CHR, o Serviço Social faz parte de todas as etapas que se dão no contexto do internamento, desde o NIR ao processo da alta hospitalar do(a) paciente. Cabe, portanto, 
nessa seção, a elucidação de quais são as atividades exercidas pelo Serviço Social em cada uma das etapas, bem como seu papel enquanto parte de uma equipe multidisciplinar.

Enquanto parte integrante do NIR, o Serviço Social é responsável pela avaliação do que envolve a questão sócio-familiar do(a) paciente, podendo, a partir da avaliação feita pela equipe médica acerca das questões clínicas, haver uma deliberação em conjunto sobre a realização ou não da avaliação do(a) paciente para fins de reabilitação na instituição.

Já no processo de avaliação, cabe ao Serviço Social verificar a retaguarda familiar, uma vez que uma das exigências e condições para a elegibilidade para o internamento é a presença de um(a) cuidador(a) vinte e quatro horas por dia com o(a) paciente. Assim sendo, nesse primeiro momento, o(a) assistente social tem como principal tarefa situar ao(a) paciente e/ou ao(a) familiar presente que essa não se trata unicamente de uma exigência baseada na rigidez, mas sim de algo que reflete a própria finalidade da instituição enquanto sendo um hospital de reabilitação. Nesse momento, entre os instrumentos e técnicas utilizadas podem ser destacadas a orientação e o prontuário social.

Posterior à avaliação, ocorre o momento da acolhida inicial, executada pelo Serviço Social de modo a reforçar a informação fornecida anteriormente ao(a) paciente e/ou ao(a) familiar presente quanto à obrigatoriedade da presença do(a) cuidador(a)a todo momento, abrangendo, porém, outras dimensões dessa necessidade. É nesse momento que o(a) assistente social aprofunda a reflexão sobre o papel do(a) cuidador(a), destacando a importância de se compreender que se trata de um novo momento na vida do(a) paciente, de uma fase que interrompeu a anterior e que há, a partir de então, uma série de coisas que deverão ser modificadas na vida dele(a) bem como na vida da família, e situa, portanto, que devido a isso cabe ao(a) cuidador(a) estar presente para aprender com a equipe técnica a lidar com todas as circunstâncias e limitações que antes não existiam, mas que agora passam a existir. Também é no momento da acolhida inicial que são repassadas, por via oral e escrita, as normas e regras do internamento, como horários e condicionantes referentes à visitação, e colhidas informações do(a) paciente e a respeito de seu contexto socioeconômico familiar, por meio do processo da orientação e do preenchimento de uma ficha de responsabilidade pela internação do(a) paciente.

No processo de reabilitação, o Serviço Social não executa atividades médicas com o(a) paciente, uma vez que isso não estaria de acordo com as competências e atribuições estabelecidas nos artigos $4^{\circ} \mathrm{e}$ $5^{\circ}$ da Lei de Regulamentação da Profissão (Lei n 8.662/93) e no Código de Ética Profissional, tampouco com os parâmetros estabelecidos pelo Conselho Federal de Serviço Social (CFESS) para a atuação de assistentes sociais na política de saúde.

Assim, o(a) assistente social se encontra enquanto profissional de referência dentro de uma equipe multidisciplinar como sendo aquele(a) responsável tanto pela garantia e defesa dos direitos do(a) paciente como de seu(a) cuidador(a) e/ou família, realizando visitas ao leito periódicas com o intuito de verificar 
possíveis demandas que possam vir a surgir, podendo, assim, viabilizar os encaminhamentos necessários por meio de articulação com a rede socioassistencial. Além disso, a partir da relação estabelecida com a equipe multidisciplinar, é possível verificar ainda outras demandas e lançar mão de intervenções em conjunto, somando informações e aprendizados.

No que tange todo o processo da reabilitação, o(a) assistente social se utiliza da escuta qualificada, das visitas ao leito, do acolhimento grupal, das orientações, reuniões e atas, relatório social, observação participante, entre outros instrumentos e técnicas.

Diante das atividades expostas, bem como das diversas demandas que podem surgir,

O profissional precisa ter clareza de suas atribuições e competências para estabelecer prioridades de ações e estratégias, a partir de demandas apresentadas pelos usuários, de dados epidemiológicos e da disponibilidade da equipe de saúde para ações conjuntas (CFESS, 2010, p. 43).

Assim, é exigido do(a) assistente social no contexto do internamento de um Centro Hospitalar de Reabilitação um vasto conhecimento acerca dos fundamentos da profissão, do que representa e envolve a instrumentalidade, das normativas que respaldam o exercício profissional, e, ainda, do Projeto ÉticoPolítico Profissional. Além disso, também é requerido conhecimento e capacidade de articulação em rede, a fim de que se possa realizar os encaminhamentos necessários, numa postura que busque articular todos esses saberes visando, sempre, a garantia e defesa de direitos dos(as) usuários(as).

\subsection{O USO DOS INSTRUMENTOS DE TRABALHO INDIRETOS PELO(A) ASSISTENTE SOCIAL NO INTERNAMENTO DE UM CHR: CONTRIBUIÇÕES}

Cabe aqui, por meio do reforço da seção 2.1.1 dessa pesquisa, que constata a importância dos instrumentos de trabalho indiretos para o registro e documentação das atividades profissionais, viabilizando, assim, a sistematização da prática do(a) assistente social, elencar as contribuições que seu uso traz no âmbito do internamento de um Centro Hospitalar de Reabilitação em duas dimensões: numa primeira, em que destaca-se relevância para a própria prática profissional, pois oportuniza-se o diálogo e troca de informações entre os(as) assistentes sociais do referido espaço socioocupacional, o aprimoramento do exercício profissional e a (re)afirmação do papel do Serviço Social dentro do internamento; e numa segunda, para com a partilha de informações entre a equipe multiprofissional bem como para com a produção de informações para e acerca da instituição, contribuindo com seu processo identitário.

Entre os principais instrumentos de trabalho indiretos utilizados pelo Serviço Social no referido espaço socioocupacional estão o prontuário social, utilizado no momento da avaliação, que é o primeiro instrumento a colher dados a respeito do(a) paciente, tais como informações básicas de identificação e de 
seu quadro clínico, abrangendo a questão da elegibilidade para o internamento na instituição e demais informações cabíveis; a ficha de responsabilidade pela internação do(a) paciente, utilizada no momento do acolhimento inicial, cujas informações aprofundam o conhecimento acerca do contexto socioeconômico familiar do(a) paciente e envolvem outros dados que possam ser relevantes, bem como consta a assinatura do(a) cuidador responsável e do(a) assistente social, firmando um compromisso de ambas as partes em prover cuidados (de diferente natureza) ao(a) paciente; a ficha de acompanhamento das visitas feitas aos leitos, em que se destacam as condutas e demandas referentes às visitas realizadas, constando também informações acerca do plano terapêutico e transporte de alta; o relatório social, que relata as intervenções realizadas, seus desdobramentos e dados coletados; e o livro de plantão ou de registro, que se constitui num instrumento profissional de suma relevância, uma vez que é a partir dele que cada assistente social registra e acompanha o andamento das atividades e intervenções executadas pelo Serviço Social. Há, ainda, outro instrumento de registro, o prontuário eletrônico, que seria o Sistema de Gestão Hospitalar e Ambulatorial do SUS (GSUS), um dos meios em que o(a) assistente social pode partilhar com a equipe multidisciplinar quais atividades realizou referente a cada paciente, resguardadas as informações sigilosas, bem como se informar quanto ao que é executado por cada área.

Percebe-se que cada instrumento indireto utilizado possui uma finalidade específica e é, consequentemente, utilizado em momentos específicos. Isso requer pensar que nem sempre será o(a) mesmo(a) profissional a atender e a acompanhar o(a) paciente quando houver uma intervenção por parte do Serviço Social, e é nesse sentido que o registro e documentação das atividades, que implica na correta e adequada utilização dos instrumentos indiretos, se constitui em objeto de diálogo entre os(as) assistentes sociais. Tal constatação faz sentido frente ao que dizem Ihara e Liberato (2010) quando estas afirmam que

Todas as abordagens sejam individuais, grupais ou aquelas realizadas em nível de comunidade, devem ser registradas para permitir continuidade da ação profissional que permitirá analisar as diretrizes da entidade, os problemas encontrados, e a qualidade do atendimento (IHARA; LIBERATO, 2010, p. 15).

Nesse sentido, a partir do momento em que se tem sistematizadas as informações do(a) paciente e de seu contexto socioeconômico familiar, as ações desenvolvidas, encaminhamentos realizados, objetivos concretizados e até mesmo desafios encontrados no desenvolvimento de alguma intervenção, viabiliza-se um processo de comunicação entre os(as) profissionais, que, como consequência, permite alavancar as possibilidades de atuação, num processo de troca de informações que enriquece a prática, uma vez que cada ação explicita demandas particulares e requer do(a) profissional intervenções específicas. Assim, para além de o(a) profissional se situar quanto ao andamento e execução das atividades do(a) colega, sendo capaz de dar continuidade naquilo que for necessário, é possível que ocorra um aprendizado no que 
se refere às atitudes e providencias tomadas e à postura profissional adotada frente às mais variadas situações, o que gera reflexões e permite aprimorar o exercício profissional.

Outra contribuição de extrema importância é quanto ao processo de afirmação e reafirmação do papel do Serviço Social nesse espaço socioocupacional a partir do que ele faz e do que ele produz em decorrência de suas ações. Portanto, a partir do que se tem produzido a profissão pode conquistar cada vez mais autonomia em sua prática, o que auxilia tanto na identificação dos limites e avanços alcançados com ela bem como da efetividade de sua contribuição.

Quanto à segunda dimensão que se pretende analisar, cabe destacar que alguns dos papéis do registro profissional enquanto documentação também são, segundo Vieira apud Ihara e Liberato (2010), os de relacionar o trabalho específico realizado pela entidade com a totalidade da realidade da comunidade, assim como de apurar as causas e efeitos dos problemas sociais, permitindo também que se avalie o resultado das técnicas e metodologias utilizadas e aperfeiçoe os(as) profissionais. É nesse sentido que a utilização dos instrumentos de trabalho indiretos para registro e documentação da prática do(a) assistente social pode contribuir também com o espaço socioocupacional.

Em primeiro lugar, destaca-se a contribuição referente à equipe multiprofissional quanto à partilha das informações do(a) paciente a partir da intervenção do(a) assistente social, na medida em que estas são, por exemplo, evoluídas no sistema GSUS, podendo ele(a) ter acesso também às ações desenvolvidas por outros(as) profissionais. Considerando que as demandas que aparecem ao Serviço Social podem não necessitar de ações somente por parte do(a) assistente social, estando a equipe dotada de conhecimento, as ações promovidas podem visar um atendimento integral e em conjunto ao(a) paciente.

Em segundo lugar, evidencia-se a contribuição quanto à produção de informações referentes ao internamento, uma vez que pode-se utilizar do conteúdo produzido para fornecer material útil à construção de indicadores e balanços de fluxo, capazes de explicitar, dentre muitas coisas, qual é o público e quais os principais traumas atendidos, quais as principais demandas que se apresentam, quais os principais encaminhamentos realizados e quais são as dificuldades enfrentadas pelo internamento e pelas equipes profissionais, colaborando com a construção da identidade do espaço socioocupacional no que tange suas características e especificidades.

Por fim, Sousa (2008) resume e reforça em poucas palavras o que foi apresentado até aqui quando pontua que o processo de registro de qualquer ação resulta num conhecimento prático que não é perdido, que garante à atividade desenvolvida relevância e visibilidade. E finaliza,

[...] sistematizar a prática e arquivá-la, é dar uma história ao Serviço Social, uma história ao(s) usuário(s) atendido(s), uma história da inserção profissional do Assistente Social dentro da instituição - é essencial para qualquer proposta de construção de um conhecimento sobre a realidade social (SOUSA, 2008 p. 129). 


\section{CONSIDERAÇÕES FINAIS}

A análise desenvolvida durante o artigo reforçou a compreensão da profisssão enquanto totalidade que abrange três dimensões essenciais, evidenciando entre estas a dimensão técnico-operativa e destacando dentro dela os instrumentos de trabalho indiretos enquanto meios de registro e documentação da prática profissional, e que, portanto, contribuem para sua sistematização.

Conforme o objetivo da pesquisa consistiu em traçar a relação destes instrumentos e sua utilização pelo(a) assistente social no contexto do internamento de um Centro Hospitalar de Reabilitação, se fez necessário discorrer acerca do funcionamento deste espaço socioocupacional e da inserção do Serviço Social nele, tomando como exemplo o internamento do Centro Hospitalar de Reabilitação Ana Carolina Moura Xavier - CHR, o que demonstra as características e especificidades do espaço e da atuação do(a) assistente social nesse contexto.

Foi possível, a partir da constatação do papel dos instrumentos de trabalho indiretos enquanto meios de registro e documentação da prática profissional, considerar essa atividade não somente como uma parte mecanizada do trabalho, ou seja, meramente técnica, mas sim algo que muito agrega para a prática do(a) assistente social no referido espaço socioocupacional em duas dimensões.

Destacou-se, em primeiro lugar, a contribuição da documentação do exercício profissional para a própria prática profissional quanto à comunicação entre os(as) assistentes sociais do internamento, o que permite uma continuidade e constância na execução das ações; quanto à constante e permanente avaliação e reformulação da prática, pautadas no aprimoramento das intervenções e do exercício profissional; e por último, quanto à afirmação e reafirmação do papel do Serviço Social no internamento, pois é possível ter claro a partir do que se tem produzido quais são suas competências e atribuições e qual a efetividade de suas ações.

Em segundo lugar, evidenciou-se as contribuições referentes à equipe multiprofissional e ao espaço socioocupacional em si, uma vez que os dados e informações registrados e documentados pelo(a) assistente social acerca de suas intervenções podem subsidiar a equipe com elementos que colaborem para uma reflexão conjunta a respeito das necessidades e das ações e condutas para com os(as) pacientes e/ou cuidadores(as), bem como podem fornecer importantes informações acerca do espaço institucional, o que contribui grandemente com o processo de construção da identidade do internamento. 


\section{REFERÊNCIAS}

ABEPSS. Diretrizes gerais para o curso de Serviço Social. Rio de Janeiro, 1996. Disponível em: $<$ http://www.abepss.org.br/arquivos/textos/documento_201603311138166377210.pdf $>$. Acesso em: 08 abr. 2019.

\section{CFESS. Parâmetros para Atuação de Assistentes}

Sociais na Política de Saúde. Brasília, 2010. Disponível em: $<\mathrm{http}$ //www.cfess.org.br/arquivos/Parametros_para_a_Atuacao_de_Assistentes_Sociais_na_Saude.pdf $>$. Acesso em: 10abr. 2019.

GUERRA, Yolanda. Instrumentalidade do processo de trabalho e Serviço Social. In:

Revista Serviço Social e Sociedade. n. 62. São Paulo: Cortez, 2000.

A instrumentalidade no trabalho do assistente social. 2007. 16 p. Disponível em: $\overline{<\mathrm{http}}$ //unesav.com.br/ckfinder/userfiles/files/Yolanda\%20Guerra\%20instrumentalid.pdf $>$. Acesso em: 08 abr. 2019.

. Apresentação. In: SANTOS, Cláudia M. dos; BACKX, Sheila;

GUERRA, Yolanda (Org.). A dimensão técnico-operativa no Serviço Social: desafios contemporâneos. Juiz de fora: Ed. UFJF, 2012. p.9-13.

IAMAMOTO, Marilda V. O debate contemporâneo do Serviço Social e a ética profissional. In: BONETTI, Dilséa et al. (Org.). Serviço Social e ética: convite a uma nova práxis. 4. ed. São Paulo: Cortez, 2001. p.87-104.

IHARA, Míriam O.; LIBERATO, Elizabeth M. A Documentação em Serviço Social na Perspectiva da Tecnologia da Informação. Revista UniVap, v.16, n.28, 2010. p. 13-19. Disponível em: $<$ https://www.univap.br/univap/pro_reitorias/int_uni_soc/revista/RevistaUnivap28.pdf $>$. Acesso em: 11 abr. 2019.

INTERNAMENTO. Hospitaldereabilitacaodoparana.saude.pr.gov. Disponível em: $<$ http://www.hospitaldereabilitacaodoparana.saude.pr.gov.br/modules/conteudo/conteudo.php?conteudo= 16>. Acesso em: 08 abr. 2019.

MIOTO, Regina C.; LIMA, Telma C. A dimensão técnico-operativa do Serviço Social em foco: sistematização de um processo investigativo. Revista Textos \& Contextos. Porto Alegre. v. 8. n.1. p. 2248. jan./jun. 2009. Disponível em: <https://www.redalyc.org/html/3215/321527164003/>. Acesso em: 19 abr. 2019.

SANTOS, Cláudia M. dos. Os instrumentos e técnicas: mitos e dilemas na formação profissional do assistente social no Brasil. Tese (Doutorado em Serviço Social) - Centro de Filosofia e Ciências Humanas, Escola de Serviço Social. Universidade Federal do Rio de Janeiro, Rio de Janeiro: 2006. 254 p.

. A dimensão técnico-operativa do Serviço Social: questões para reflexão. In: SANTOS, Cláudia M. dos; BACKX, Sheila; GUERRA, Yolanda (Org.). A dimensão técnico-operativa no Serviço Social: desafios contemporâneos. Juiz de fora: Ed. UFJF, 2012. p.15-38. 
A dimensão técnico-operativa e os instrumentos e técnicas no Serviço Social. In: Revista Conexão Geraes. n. 3. Belo Horizonte: CRESS-MG, 2013.Disponível em: <http://cressmg.org.br/publicacoes/Home/PDF/62>. Acesso em: 08 abr. 2019.

SOUSA, Charles T. A prática do assistente social: conhecimento, instrumentalidade e intervenção profissional. Emancipação, Ponta Grossa, 2008. p. 119-132. Disponível em: $<\mathrm{http}$ ://www.unirio.br/unirio/cchs/ess/Members/altineia.neves/instrumentos-e-tecnicas-em-servicosocial/sousa-charles-t-a-pratica-do-assistente-social-conhecimento-instrumentalidade-e-intervencao-profissional/view>. Acesso em: 10 abr. 2019. 